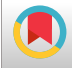

\title{
Reasons Behind the Tendency Toward the Only Child in Iranian Families: A Conventional Content Analysis Study
}

\author{
Mohammad Yousefi-Nayer ${ }^{1}$, Jalal Poorolajal ${ }^{2}$ and Zahra Cheraghi ${ }^{2, *}$ \\ ${ }^{1}$ Public Health Department, School of Public Health, Hamadan University of Medical Sciences, Hamadan, Iran \\ ${ }^{2}$ Department of Epidemiology, Modeling of Non-Communicable Diseases Research Center, School of Public Health, Hamadan University of Medical Sciences, Hamadan, Iran \\ "Corresponding author: Department of Epidemiology, Modeling of Non-Communicable Diseases Research Center, School of Public Health, Hamadan University of Medical \\ Sciences, Hamadan, Iran. Email: cheraghiz@ymail.com
}

Received 2018 August 04; Revised 2019 April 29; Accepted 2019 May 10.

\begin{abstract}
Background: The "only child" phenomenon can swiftly reduce the fertility rate in Iran, disrupt the age pyramid, and be followed by irreparable social and economic harms.

Objectives: The goal of this qualitative study was to understand the reasons behind the tendency toward the only child in the Iranian society.

Methods: The conventional content analysis was done following the semi-structured interview. Maximum opportunistic sampling was done. The variables taken into consideration for maximum variation were sex, age, education, and occupation.

Results: Overall, 46 interviews were conducted. Most of the participants underscored the role of economic causes as the most effective factor. They emphasized that the rise in costs of living was the main factor behind the employment of both parents, particularly the mother, which subsequently robs her of adequate time and patience for parenting.

Conclusions: The most important factors contributing to the lack of tendency toward family fertility were, economic factors, rising marriage age; inadequate support for working mother, and being away from relatives. Thus, if policy makers are bent towards intervening in fertility and neutralizing it, they must make the necessary arrangements to improve the families' economic status.
\end{abstract}

Keywords: Only Child, Qualitative Research, Iran

\section{Background}

The Population Reference Bureau has presented a short analysis of population indices, based on which developed countries will be faced with reduced populations of youth in the years to come. Based on this report, in addition to developed countries, Iran too will have to face the problem of increasing age, one which has been repeatedly warned about in recent years $(1,2)$. In addition, if Iran continues to replace its population with the current trend, and if it adopts no program to balance it (3-5).

Demographic experts have recognized different factors in the reduction of birth rate and in general the fertility rate in the past two decades, including: raised mean age of marriage among women, relative rise in children's costs, etc. (6-11).

\section{Objectives}

The objective of this study was therefore to understand the reasons behind the tendency toward having an onlychild among the Iranian community.

\section{Methods}

A qualitative study was conducted in the form of conventional content analysis and through semi-structured interviews. Maximum opportunistic sampling was done. Sampling began as convenience sampling and continued as purposive sampling. Only child families were selected through medical centers.

In addition, the researcher documented the details of the research and described the stages of research from beginning to end in complete detail to allow its assessment by an outside observer $(12,13)$. Informed consent was taken from all the participants upon describing the research goals in writing and orally. The interviews were conducted in a quiet place, free of stress, by 10 interviewers, separately.

\section{Results}

After compilation and combination of similar codes, which extracted codes by the interviewers (Appendix 1 in Supplementary File). These were classified into following 
subcategories: economic reasons, parental reasons, cultural reasons, social reasons, and political reasons (Appendix 2 in Supplementary File).

\subsection{Economic Reasons}

Some of these economic reasons were, occupation, occupational security, simultaneous employment of both parents -particularly the mother- to meet financial needs, inadequate income inadequate finances for parenting, inflation, and lack of necessary facilities for the children. Some of the parents' statements are as follows: "From the very beginning, parenting costs, including daycare and schooling expenses, are very heavy for low-income families like us".

\subsection{Parental Reasons}

Some of the parental issues that inhibited the tendency toward childbearing were, the father's role lack of adequate time for parenting due to simultaneous employment of both parents -particularly that of the mother. One parent who was an academic lecturer and had one child said: "The rising age marriage itself is a big problem; instead of 20 it has reached the age of 35. The father's older age leaves him with lesser patience for childrearing".

\subsection{Cultural Reasons}

Cultural factors were among other background factors encouraging parents toward lower childbearing rates; pedocentricism and the apprehension of facing it, lack of familial support and nearby relatives for childcare and subsequently the evolution of the nuclear family system, perfectionism in lifestyle, parenting and creating facilities for children, changes in lifestyle.

\subsection{Social Reasons}

Social issues were less emphasized than the other issues; only three codes were extracted in this subcategory, and included issues such as social incidents and social freedom. One couple exclaimed: "Unfortunately, every other day we hear unpleasant news about social harms regarding children, most of which occur due to the parents' lack of proper responsibility toward the children".

\subsection{Political - Governmental Reasons}

Only twelve codes were extracted in this category, including, governmental support and the family planning policy and rules. One couple stated: "Until a decade ago, most of the country's population control authorities promoted the famous "two children are enough" slogan, and now all the definitions and preferences have changed".

\section{Discussion}

Based on the slow population growth scenario depicted by the United Nations in 2010, if Iran continues to replace its population with the current trend and if it adopts no program to balance it, in the next 80 years, it will have a population of 31 million, $47 \%$ of which will consist of individuals aged over 60 years $(14,15)$.

Most of the participants in this study had addressed the role of economic causes as the most influential. Dorahaki et al., showed a negative correlation between the financial burden of childrearing and the fertility intent among women (16). McAllister et al., too showed that after increasing age, some socioeconomic factors such as economic difficulties were the most important challenges couples faced in their fertility intent (17).

The increasing age of marriage and lack of patience for childrearing was repeatedly emphasized by the participants. Official statistics also indicate the significant rise in the mean marriage age, both among men and women; during the past ten years, the mean marriage age has risen from 19 years to 26 (15). Multiple studies have shown the negative impact of rising marriage age on reduced fertility (16-20).

\subsection{Conclusions}

The most important factors contributing to the lack of tendency toward family fertility were, economic factors, rising marriage age, inadequate support for working mothers, and being away from relatives.

\section{Supplementary Material}

Supplementary material(s) is available here [To read supplementary materials, please refer to the journal website and open PDF/HTML].

\section{Footnotes}

Conflict of Interests: The authors declare no conflict of interests.

Ethical Approval: The Vice Chancellor of Research and Technology as well as the local Ethics Committee of Hamadan University of Medical Sciences approved the study (IR.UMSHA.REC.1396.296).

Funding/Support: The Vice Chancellor of Research and Technology of Hamadan University of Medical Sciences supported this study. 


\section{References}

1. Population Reference Bureau. World population data sheet 2013. 2013.

2. Noroozian M. The elderly population in iran: an ever growing concern in the health system. Iran J Psychiatry Behav Sci. 2012;6(2):1-6. [PubMed: 24644476]. [PubMed Central: PMC3940007].

3. Parsanezhad E, Namavar Jahromi B, Zare N, Keramati P, Khalili A, Parsa-Nezhad M. Epidemiology and etiology of infertility in Iran, systematic review and meta-analysis. J Women Health Issues Care. 2013;2(6). doi: 10.4172/2325-9795.1000121.

4. Erfani A, McQuillan K. Rapid fertility decline in Iran: Analysis of intermediate variables. J Biosoc Sci. 2008;40(3):459-78. doi: 10.1017/S002193200700243X. [PubMed: 17850688].

5. Vahidnia F. Case study: Fertility decline in Iran. Popul Environ. 2007;28(4-5):259-66. doi: 10.1007/s11111-007-0050-9.

6. Mirzaie M. swings in fertility limitation in Iran. Critiq Crit Middle E Stud. 2005;14(1):25-33. doi: 10.1080/10669920500056973.

7. Hoodfar $\mathrm{H}$, Assadpour S. The politics of population policy in the Islamic Republic of Iran. Stud Fam Plann. 2000;31(1):19-34. [PubMed: 10765535].

8. Karamouzian M, Sharifi H, Haghdoost AA. Iran's shift in family planning policies: Concerns and challenges. Int J Health Policy Manag. 2014;3(5):231-3. doi: 10.15171/ijhpm.2014.81. [PubMed: 25337596]. [PubMed Central: PMC4204741].

9. Jalal Abbasi-Shavazi M, McDonald P. Fertility decline in the Islamic Republic of Iran: 1972-2000. Asian Popul Stud. 2006;2(3):217-37. doi: $10.1080 / 17441730601073789$.

10. Salehi-Isfahani D, Abbasi-Shavazi MJ, Hosseini-Chavoshi M. Family planning and fertility decline in rural Iran: The impact of rural health clinics. Health Econ. 2010;19 Suppl:159-80. doi: 10.1002/hec.1613. [PubMed: 20552711].

11. Karamouzian M, Haghdoost AA. Population control policies in Iran. Lancet. 2015;385(9973):1071. doi: 10.1016/S0140-6736(15)60596-7.
[PubMed: 25797554].

12. Denise F, Beck CT, Hungler BP. Essentials of nursing research: Methods, appraisal, and utilization. Lippincott; 2001.

13. Speziale HS, Streubert HJ, Carpenter DR. Qualitative research in nursing: Advancing the humanistic imperative. Lippincott Williams \& Wilkins; 2011.

14. Hosseini-Chavoshi M, Abbasi-Shavazi MJ, McDonald P. Fertility, marriage, and family planning in Iran: Implications for future policy. Popul Horiz. 2016;13(1):31-40. doi: 10.1515/pophzn-2016-0005.

15. Statistical Center of Iran. 2017. Available from: https://www.amar.org. ir/.

16. Dorahaki A. [Determinants of women's ideal fertility: Study of women 15 to 49 year old in Nasimshar city in 2015]. Razi J Med Sci. 2016;22(141):59-68. Persian.

17. McAllister L, Gurven M, Kaplan H, Stieglitz J. Why do women have more children than they want? Understanding differences in women's ideal and actual family size in a natural fertility population. Am J Hum Biol. 2012;24(6):786-99. doi: 10.1002/ajhb.22316. [PubMed: 22987773]. [PubMed Central: PMC3806294].

18. Sibanda A, Woubalem Z, Hogan DP, Lindstrom DP. The proximate determinants of the decline to below-replacement fertility in Addis Ababa, Ethiopia. Stud Fam Plann. 2003;34(1):1-7. [PubMed: 12772441].

19. Behjati-Ardakani Z, Navabakhsh M, Hosseini SH. Sociological study on the transformation of fertility and childbearing concept in Iran.J Reprod Infertil. 2017;18(1):153-61. [PubMed: 28377894]. [PubMed Central: PMC5359852].

20. Ezeh AC, Mberu BU, Emina JO. Stall in fertility decline in Eastern African countries: regional analysis of patterns, determinants and implications. Philos Trans R Soc Lond B Biol Sci. 2009;364(1532):29913007. doi: 10.1098/rstb.2009.0166. [PubMed: 19770151]. [PubMed Central: PMC2781835]. 